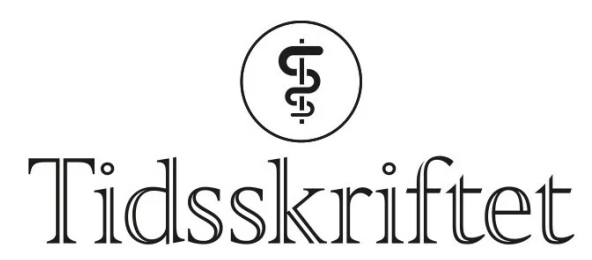

DEN NORSKE LEGEFORENING

\title{
En ung kvinne med øvre gastrointestinal blødning
}

NOE Å LARE AV

\section{VIKAS KUMAR SARNA}

Vikas Kumar Sarna (f. 1980) er lege i spesialisering i indremedisin og i gastroenterologi ved Medisinsk avdeling, Diakonhjemmet sykehus.

Forfatter har fylt ut ICMJE-skjemaet og oppgir ingen interessekonflikter.

Email:v.sarna@hotmail.com

Diakonhjemmet sykehus

Medisinsk avdeling

\section{NJAAL STRAY}

Njaal Stray (f. 1944) er spesialist i gastroenterologi. Han er seksjonsoverlege ved Medisinsk avdeling, Diakonhjemmet sykehus.

Forfatter har fylt ut ICMJE-skjemaet og oppgir ingen interessekonflikter.

Diakonhjemmet sykehus

Medisinsk avdeling

En ung, tidligere frisk kvinne ble innlagt i medisinsk avdeling med hematemese og ustabil sirkulasjon. Hemoglobinnivået var lavt, og det var nødvendig med rask tilførsel av væske og blod. Ved første gastroskopi ble det ikke påvist noe sikkert blødningsfokus. Tilstanden forverret seg, noe som skapte en krevende situasjon på intensivavdelingen og gastrolaboratoriet - for så å resultere i en overraskende diagnostisk avklaring.

En ung kvinne ble innlagt i medisinsk avdeling etter å ha kastet opp små mengder med friskt blod iblandet koagler, og med hemoglobinnivå på 7,7 g/10o ml (referanseverdi 11,7-15,3 g/10o ml). Kvelden før hadde hun vcert på fest og inntatt noe alkohol. Om morgenen innleggelsesdagen følte hun seg dårlig, og på vei til toalettet hadde hun en ncersynkope. Hun kontaktet legevakten. Da ambulansen ankom, synkoperte hun ved forsøk på å reise seg. Hun hadde tidligere ikke vart alvorlig syk og brukte ingen faste medisiner.

Ved innkomst (dago) var hun blek med lett redusert allmenntilstand, blodtrykk på 102/7o mm Hg som falt til 88/44 mm Hg, og puls mellom 105 slag/min og $122 \mathrm{slag} / \mathrm{min}$. Den kliniske undersøkelsen var upåfallende, inkludert negative funn over abdomen. Det var normaltutseende avføring, men 
momentant positiv test på okkult blod. Blodprøver viste $\mathrm{Hb} 6,2 \mathrm{~g} / 100 \mathrm{ml}$ og $\mathrm{MCV} 72 \mathrm{fl}$ (referanseverdi 82-98fl). Øvrige blodprøver var alle normale.

Viktige momenter i den initiale anamnesen var spørsmål om komorbiditet og medikamentbruk (NSAID-preparater, acetylsalisylsyre og antikoagulantia). Vår pasient hadde følt seg fullstendig frisk tidligere, og hun hadde ikke brukt noen medisiner. Videre var det viktig å få en oversikt over antatt mengde blodtap. Med en aktuell hemoglobinverdi på 6,2 g/10o ml og en antatt utgangsverdi på ca. $13 \mathrm{~g} / 100 \mathrm{ml}$, kunne man anslå et omtrentlig blodtap på minst $40 \%$ av hennes totale blodvolum. Dette forutsatte at kompensatorisk hemodilusjon hadde rukket å inntre. Dersom et blodtap av en slik størrelse hadde kommet akutt, ville det medført sirkulatorisk ustabilitet. Mister man dette blodvolumet over tid, kan kroppen rekke å iverksette korrigerende tiltak. I en slik kompensert situasjon kan en akutt mindre blødning være alvorlig. Vår pasient kom inn med anamnese på sparsom gastrointestinal blødning med lav MCV-verdi, men med påfallende lavt hemoglobinnivå og i tillegg tegn på sirkulatorisk ustabilitet. Det talte for at hun kanskje over tid hadde hatt et okkult blodtap og nå hadde en akutt blødning.

Hematemese antyder alltid blødningslokalisasjon i øvre gastrointestinaltractus, dvs. proksimalt for Treitz' ligament. Tentative diagnoser var blødning fra peptisk sår, MalloryWeiss lesjon (brekningsindusert mucosaskade på overgangen oesophagus/magesekk), tumorer og karmalformasjoner. Hos et ungt menneske uten tegn på leversykdom var variceblødning en mindre aktuell differensialdiagnose.

Pasienten ble lagt $i$ intensivavdelingen, fikk parenteral vceske og $i$ alt fire poser SAGMAN-blod første døgn. I tillegg ble det startet behandling med pantoprazol intravenøs bolusdose $80 \mathrm{mg}$, etterfulgt av vedlikeholdsinfusjon $8 \mathrm{mg} / \mathrm{t}$, pga. mistanke om blødende ulcus.

Sykehuset manglet vaktberedskap innen skopi da pasienten ble lagt inn. Samarbeidende sykehus med slik vaktberedskap ble ikke kontaktet da tilstanden raskt stabiliserte seg etter at pasienten ble flyttet til intensivavdelingen. I løpet av første natt var det kommet regelmessig med moderate mengder melena, men ingen ny hematemese. Hemoglobinverdien var om morgenen (dag 1) på $8,5 \mathrm{~g} / 10 \mathrm{~m} \mathrm{ml}$. Ved gastroskopi ble det ikke funnet spor av blod ned til nedre del av duodenum, og det ble heller ikke påvist potensielle blødningskilder. Man fant kun lettgradig refluksøsofagitt, et lite hiatushernie og et lite overflatisk ulcus $(<4 \mathrm{~mm})$ i antrum uten blødningsstigmata. Hurtig ureasetest med henblikk på Helicobacter pylori var negativ.

Det var noe overraskende at man ved gastroskopi ikke fant potensiell blødningskilde eller spor av blod i øvre gastrointestinaltractus. Imidlertid var det en mulighet for at blødningskilden var så liten (eventuelt hadde en slik beliggenhet) at den var blitt oversett. Muligheten for at det var to blødningskilder, en minimal blødningskilde i øvre gastrointestinaltractus og en større blødningskilde distalt for duodenum, ble også vurdert. Det var derfor aktuelt med ny gastroskopi før eventuell koloskopi.

Grunnet stabil hemoglobinverdi ble pasienten flyttet til post. Samme kveld falt hemoglobinverdien til $6,5 \mathrm{~g} / 100 \mathrm{ml}$. Det var uendret pågående lavgradig melena. Hun ble gitt to nye poser med SAGMANblod og mer veeske. Tidlig neste morgen ( dag 2 ) ble det utført en ny gastroskopi. Igjen var det upåfallende forhold ned til nedre del av duodenum. Men idet skopet ble trukket tilbake begynte det å blø kraftig fra duodenum. Oversikten ble raskt betydelig forstyrret. Mistenkt blødningsfokus ble lokalisert til mediale vegg like distalt for bulbuskneet. Det ble injisert fortynnet adrenalin $(0,1 \%) i$ flere depoter, og etter hvert oppnådde man hemostase. Det ble også injisert polydocanol 1\%, o,5 $\mathrm{ml} \mathrm{i}$ hvert depot mot antatt blødningsfokus. Imidlertid var det ingen synlige slimhinnelesjoner. Pasienten ble gitt to nye poser med SAGMAN-blod, og man startet i tillegg behandling med traneksamsyre 1,5 $\mathrm{g} \times 4$ intravenøst. Ny gastroskopi på ettermiddagen samme dag viste fortsatt frisk blødning fra samme område i duodenum. Det ble igjen injisert fortynnet adrenalin, noe som resulterte $i$ avtakende blødning. For å få bedre oversikt brukte man et ERCP-skop (optikk ut til siden). Man kunne da se sivblødning fra et punkt uten sårbunn (fig 1 ). Det ble injisert polidocanol $1 \%$, totalt $4,5 \mathrm{ml}$ à o,5 $\mathrm{ml}$ og deretter applisert argonplasmakoagulasjon (APC) nøyaktig mot det blødende punktet inntil full hemostase (fig 2 ). 


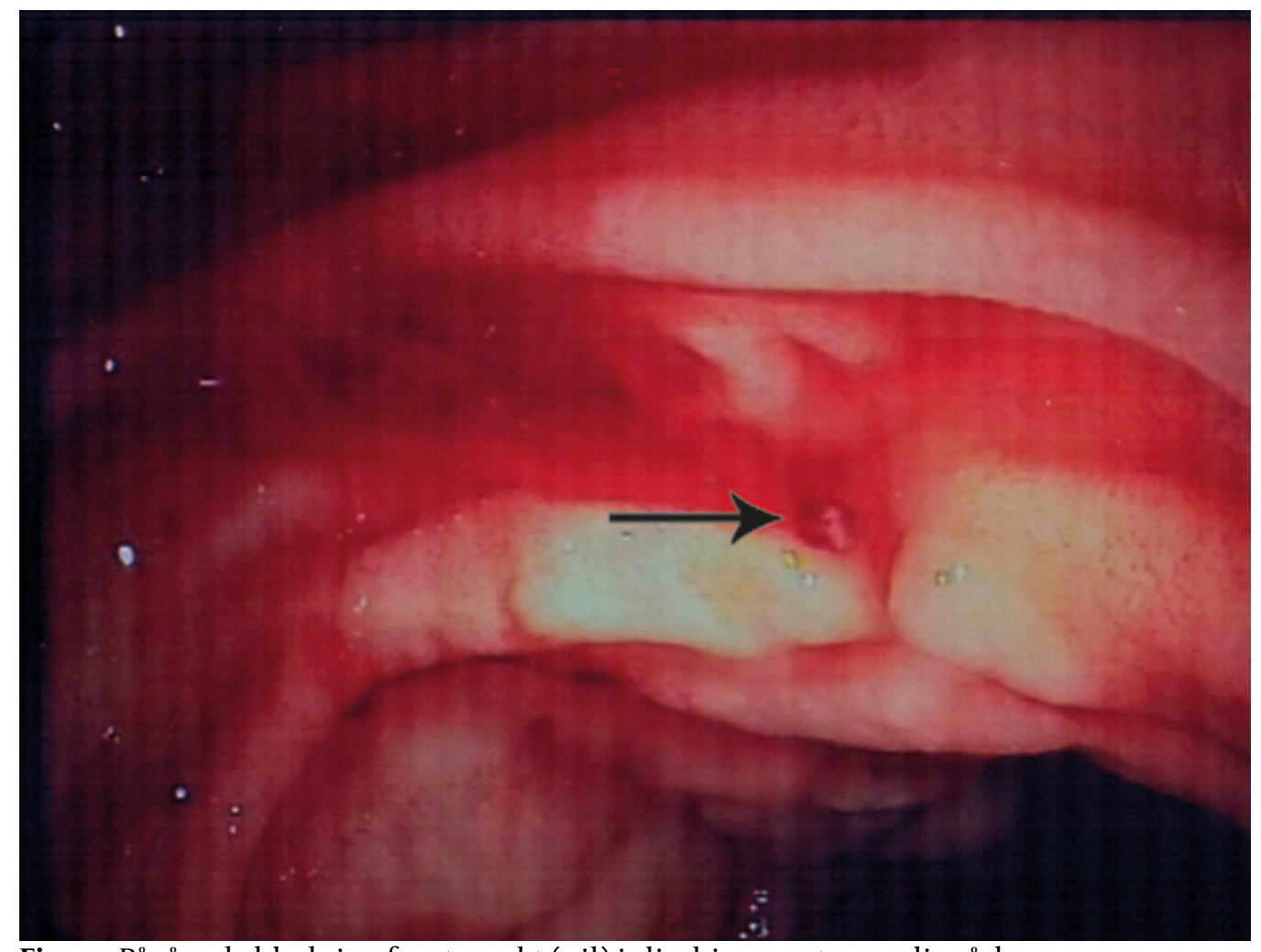

Figur 1 Pågående blødning fra et punkt (pil) i slimhinnen uten synlig sårbunn

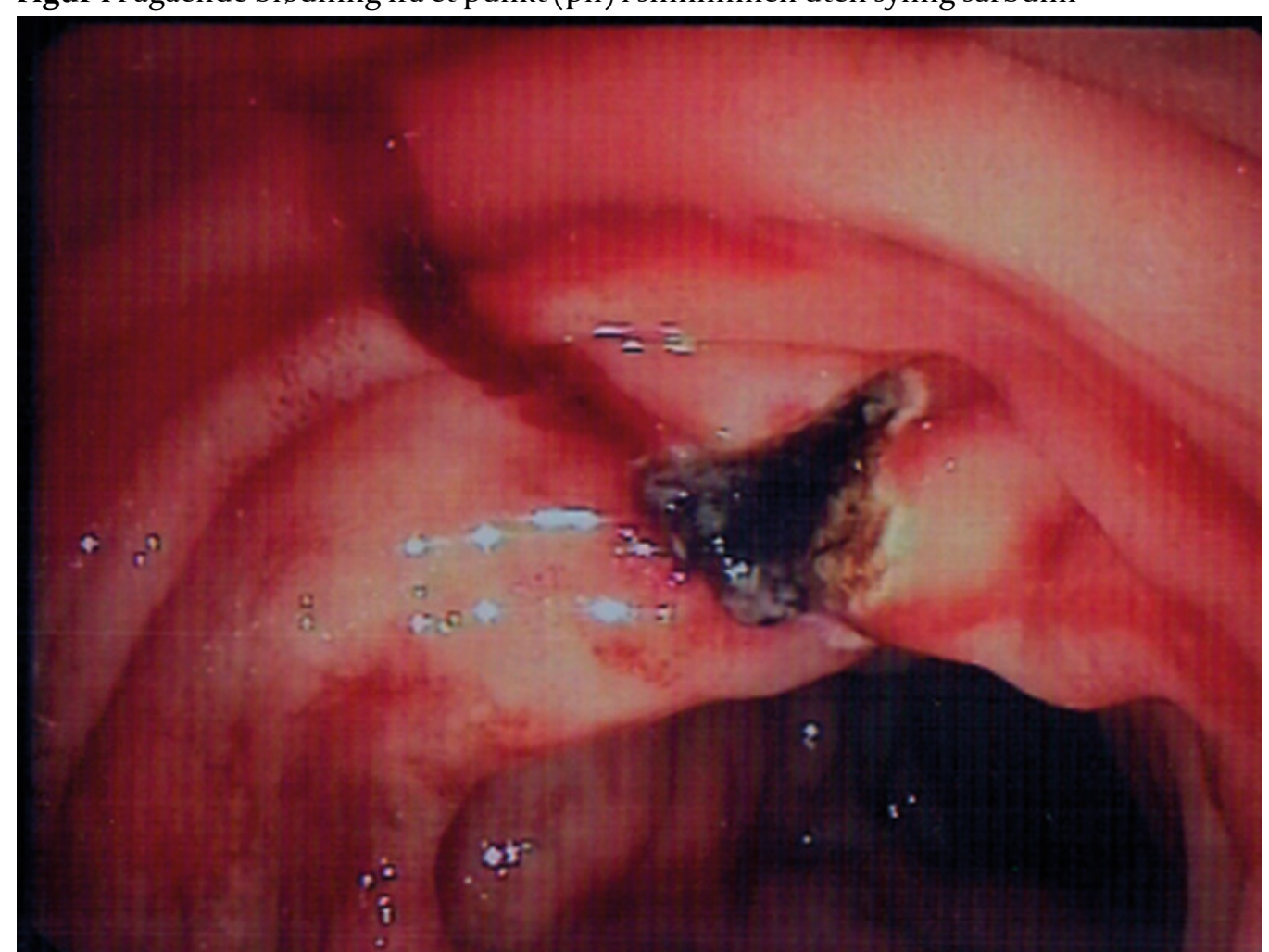

Figur 2 Hemostase etter injeksjon av Aetoxysklerol og applisert argonplasmakoagulering 


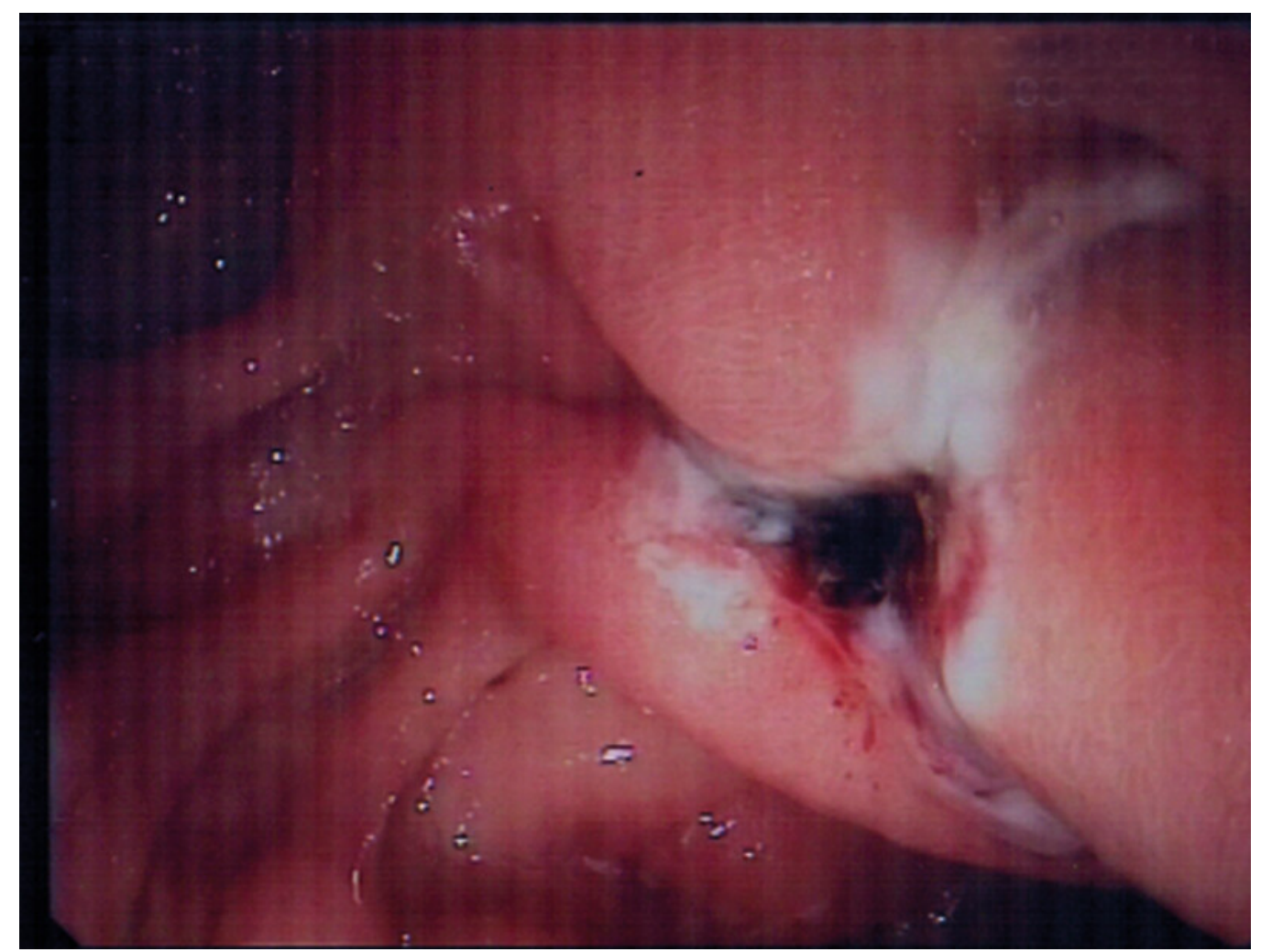

Figur 3 Kontrollgastroskopi dagen etter terapi viser at blødningen har stanset

Arteriell blødning fra en makroskopisk normal slimhinne ga en diagnostisk avklaring. Funnet var forenlig med Dieulafoys lesjon (exulceratio simplex), det vil si blødning fra en dilatert submukøs arteriole.

Pasientens hemoglobinnivå var stabilt på 7,7 g/10o ml til dagen etter(dag 3) og fortsatte å stige utover dagen $(8,4 \mathrm{~g} / 100 \mathrm{ml})$ uten ny tilførsel av blod. Det var ingen avføring/melena morgen/ettermiddag. Ny gastroskopi (nr. 4) bekreftet at blødningen var stanset (fig 3). På grunn av opplysninger i sykehistorien om mulig lettgradig hemoragisk diatese ble det konferert med hematolog, som anbefalte å ta von Willebrand-prøver i rolig fase. Det ble også konferert med revmatolog, som ikke fant holdepunkter for vaskulitt. En CT-undersøkelse av abdomen avdekket kun lett ødem i duodenalveggen.

Pasienten fikk intravenøs jerninfusjon med overgang til peroral jernbehandling og pantoprazol per os. Hun ble skrevet ut med hemoglobinverdi på 9,7 g/10o ml etter fem dagers sykehusopphold. Planlagt gastroskopikontroll var etter fire uker.

Ved fireukerskontroll kunne pasienten angi at hun ikke hadde hatt nye blødningsepisoder. Ved gastroskopi utført med ERCP-skop ble det ikke påvist patologiske tegn i slimhinnen i duodenum. Blodprøver tatt etter fire måneder viste normalisering av hematologiske variabler ( $\mathrm{Hb} 14 \mathrm{~g} / 100 \mathrm{ml}$, MCV $94 \mathrm{fl}$, ferritin $102 \mathrm{mcg} / \mathrm{l}$ (referanseverdi $10-200 \mathrm{mcg} / \mathrm{l}$ )), inkludert normale von Willebrandprøver.

\section{Diskusjon}

Dieulafoys lesjon er oppkalt etter den franske kirurgen Paul Georges Dieulafoy (1839-1911). Blødningen mener man stammer fra en unormalt dilatert submukøs arteriole på 1-3 mm (1). Etiologien er ukjent. En hypotese er at kardefekten er medfødt og at blodkaret ikke får avgitt kalibernedsettende forgreninger (2 $)$. Blødning forekommer sekundært til en makroskopisk usynlig erosjon av den overliggende slimhinnen. Endoskopisk stilles diagnosen ved tilstedeværelse av aktiv arteriell blødning, synlig kar eller fersk fastsittende trombe i makroskopisk normal slimhinne, eller i en liten slimhinnedefekt på maksimalt 3 $\mathrm{mm}(3)$. 
Vår pasient hadde tegn på kronisk okkult gastrointestinal blødning, med akutt forverring. Først ved andre gastroskopi ble det påvist blødning fra et område i duodenum som man normalt ikke får god oversikt over med et gastroskop. Ved hjelp av et ERCP-skop ble det så påvist et blødningsfokus forenlig med Dieulafoys lesjon. Dette er en sjelden, men viktig tilstand som må vurderes når man står overfor en uavklart kronisk eller akutt gastrointestinal blødning. I opptil $70 \%$ av tilfellene oppdages lesjonen etter første gastroskopi (1). Ved de resterende tilfellene vil man som regel komme i mål med gjentatte skopier, slik som hos vår pasient. Endoskopisk ultralydundersøkelse kan være et diagnostisk hjelpemiddel (2) $)$. Årsaken til at man ikke finner blødningsfokus ved første gastroskopi kan enten være at oversikten forringes av mye blod (44\%) eller at man ikke finner lesjonen (56\%) (1). Ut fra mistanke og lokal kompetanse kan man da velge å gå videre med ny gastroskopi, ballongenteroskopi, kapselendoskopi, angiografi eller technetiummerket erytrocyttscintigrafi (므). Utover dette er det lite å hente med radiologisk diagnostikk (CT, MR etc.).

I studier fra sykehusmaterialer finner man at Dieulafoys lesjon er årsaken til mellom $1 \%$ og 5,8 \% av akutte øvre gastrointestinale blødninger (4,.5). Man antar også at tilstanden er underdiagnostisert. Blødningen er ofte intermitterende og kan således være vanskelig å påvise. Presentasjonsformen er i all hovedsak hematemese og/eller melena, og hos et mindretall kan det være kun friskt blod per rectum (hematochezi). Defekten forekommer aller hyppigst i magesekken, og som regel på minorsiden innen $6 \mathrm{~cm}$ fra overgangen mellom spiserør og magesekk $(\underline{1}, 4$.). En tredel av lesjonene er utenfor magesekken $(\underline{1}, \underline{6})$. Selv om lokalisasjon i duodenum er nest hyppigst, er fokus i pars descendens svært uvanlig (7.). Lesjonen kan imidlertid forekomme i alle deler av tarmen og er også beskrevet å forekomme utenfor tarmen (1).

Pasientgruppen med Dieulafoys lesjon skiller seg lite fra gruppen med ulcus pepticum. Gjennomsnittsalderen til pasientene med Dieulafoys lesjon var i en studie 67 år, og det var en overvekt av menn (1,4). I opptil 9o \% av tilfellene er det komorbide sykdommer som iskemisk hjertesykdom, nyresvikt, diabetes, hypertensjon og leversvikt (므). Magesmerter ved Dieulafoys lesjon er imidlertid uvanlig (므), og det er ikke funnet sikker kausal sammenheng med bruk av NSAID-preparater, acetylsalisylsyre eller warfarin $(\mathbf{1}, 4$.$) .$

De viktigste differensialdiagnosene til øvre gastrointestinal blødning er nevnt ovenfor. Når man stiller diagnosen Dieulafoys lesjon ved endoskopi, har man i praksis allerede utelukket en ulcusblødning. En papillenær blødning må skilles fra en blødning utgående fra galletreet (hemobili), hvor blod vil sive ut fra papillen. Sistnevnte blødning er sjeldnere, ofte traumatisk betinget og kan ledsages av magesmerter og icterus ( $\underline{8})$.

Tidligere var kirurgi eneste kurative behandling for denne tilstanden, og historiske materialer beskriver en mortalitet på $80 \%$ (1) $)$. Endoskopisk behandling er nå blitt foretrukket behandlingsmodalitet, og fremskritt i behandlingen har medført et fall i mortalitet til 8,6\%(1). Tilgjengelige endoskopiske behandlingsalternativer kan enten være termal behandling (elektrokoagulering, argonplasmakoagulering etc.), lokal injeksjon (adrenalin og skleroterapi) eller mekanisk behandling (strikkligering og hemoklips). Hos vår pasient ble det brukt injeksjon og argonplasmakoagulering i kombinasjon.

Endoskopisk hemostase beskrives å forekomme i over $90 \%$ av tilfellene (4). Mekanisk behandling antas å være mest effektivt (1). Bruk av minst to behandlingsmetoder har vist seg å redusere reblødningsraten (11). I en studie forekom reblødning hos sju av 39 pasienter innen tre dager etter primær vellykket hemostase (9.). I en oversiktsartikkel angis reblødningsraten å ligge mellom 9\% og $40 \%$ (1). Ved reblødning foretrekker man ny endoskopisk behandling.

Endovaskulær påvisning og behandling av blødende lesjon er et alternativ til endoskopisk behandling $(\underline{6})$. Kirurgisk behandling reserveres de $5 \%$ av tilfellene som ikke responderer på endoskopisk og/eller endovaskulær behandling (11). Kirurgisk behandling består enten i omstikking eller kilereseksjon av lesjonen. Det er beskrevet oppmuntrende fremskritt 
innen laparoskopisk behandling og metoder som kombinerer peroperativ endoskopi og laparoskopi, eller laparoskopi etter forutgående endoskopisk tatovering av blødningsfokus (1).

Blødning fra Dieulafoys lesjon vil ofte by på diagnostiske og terapeutiske utfordringer. Gastrointestinal endoskopi vil i de aller fleste tilfellene kunne gi riktig diagnose og effektiv behandling. En studie med oppfølgingstid på 28 måneder har vist at prognosen er svært god hos dem som skrives ut fra sykehus etter endoskopisk hemostase (5). Mortaliteten er først og fremst knyttet til komorbide tilstander $(\underline{4}, 5)$.

\section{LITTERATUR}

1. Baxter M, Aly EH. Dieulafoy's lesion: current trends in diagnosis and management. Ann R Coll Surg Engl 2010; 92: 548-54. [PubMed] [CrossRef]

2. Jaspersen D. Dieulafoy's disease controlled by Doppler ultrasound endoscopic treatment. Gut 1993; 34: 857-8. [PubMed] [CrossRef]

3. Hyun CB. Periampullary Dieulafoy"s lesion. Hosp Physician 2005; 41: $23-7$.

4. Walmsley RS, Lee YT, Sung JJ. Dieulafoy's lesion: a case series study. World J Gastroenterol 2005; 11: 3574-7. [PubMed]

5. Baettig B, Haecki W, Lammer F et al. Dieulafoy's disease: endoscopic treatment and follow up. Gut 1993; 34: 1418-21. [PubMed] [CrossRef]

6. Alshumrani G, Almuaikeel M. Angiographic findings and endovascular embolization in Dieulafoy disease: a case report and literature review. Diagn Interv Radiol 2006; 12: 151-4. [PubMed]

7. Rana SS, Bhasin DK, Gupta R et al. Periampullary Dieulafoy's lesion: an unusual cause of gastrointestinal bleeding. JOP 2010; 11: 266-9. [PubMed]

8. Chin MW, Enns R. Hemobilia. Curr Gastroenterol Rep 2010; 12: 121-9. [PubMed] [CrossRef]

9. Lim W, Kim TO, Park SB et al. Endoscopic treatment of dieulafoy lesions and risk factors for rebleeding. Korean J Intern Med 2009; 24:318-22. [PubMed] [CrossRef]

Publisert: 2. oktober 2012. Tidsskr Nor Legeforen. DOI:10.4045/tidsskr.11.1197

Mottatt 12.10. 2011, første revisjon innsendt 28.2. 2012, godkjent 12.4.2012. Medisinsk redaktør Jon Amund Kyte.

(C) Tidsskrift for Den norske legeforening 2023. Lastet ned fra tidsskriftet.no 26. april 2023. 